\title{
A case of Greither's disease with late onset of disease: a rare presentation
}

\section{Przypadek choroby Greithera o późnym początku - rzadka postać schorzenia}

\author{
Surabhi Sinha, Prekshi Bansal, Konchok Dorjay, Gauri Vats \\ Department of Dermatology, Venereology and Leprosy, Dr. Ram Manohar Lohia Hospital and Post Graduate Institute of Medical \\ Education and Research, New Delhi, India
}

Greither's disease, also known as transgrediens et progrediens keratoderma, is a non-epidermolytic palmoplantar keratoderma with autosomal dominant inheritance, usually presenting after 2 years of age and resolving after the fifth decade. It is characterized by diffuse involvement of palms and soles with an erythematous border [1, 2].

A 22-year-old male patient, born out of a non-consanguineous marriage, presented to our outpatient department with skin thickening over both palms and soles extending to the dorsal aspect for the last 7 years (fig. 1). The skin over knees, elbows and ankle joints was also thickened (fig. 1). It was not associated with hyperhidrosis. There was no history of similar lesions in the family members. Examination revealed diffuse palmoplantar keratoderma with erythematous borders, extending onto the dorsal aspect of hands and feet. Hyperkeratotic plaques were seen on bilateral knees and elbows and tendo-achilles areas. Hair, nails and teeth were normal. Systemic examination and routine investigations were within normal limits. Skin biopsy from the palm revealed irregular acanthosis and dermal mild inflammatory infiltrate.

In 1952, Greither first reported a case of this unique clinical phenotype and named it as "keratosis extremitatum hereditaria progrediens" [3]. This was followed by a few case reports of the same entity by the name of transgrediens et progrediens in the literature [2-4]. Non-epidermolytic palmoplantar keratoderma (PPK) with erythematous border extending to the dorsum (transgrediens) and the involvement of wrist flexures (progrediens) and tendon of Achilles are the salient morphological characteristics of the disease [5]. Hyperkeratotic plaques can be present on knees and elbows. Hyperhidrosis is also commonly seen [6]. Histopathological findings are not typical for the disease and include acanthosis and orthohyperkeratosis. Although Greither's disease has a unique
Choroba Greithera, określana również jako rogowiec dłoniowo-podeszwowy postępujący z transgrediencją (keratoderma transgradienset progrediens), jest schorzeniem dziedziczonym autosomalnie dominujacco. Zwykle pojawia się po 2. roku życia i ustępuje po 5. dekadzie. Charakteryzuje się rozlanym rogowaceniem powierzchni dłoniowych rąk i podeszew stóp odgraniczonym od otoczenia rumieniowym brzegiem [1, 2].

Dwudziestodwuletni mężczyzna, urodzony w małżeństwie osób niespokrewnionych, zgłosił się do poradni z powodu zgrubienia skóry na powierzchni dłoniowej rąk i podeszwach stóp, przechodzącego także na powierzchnie grzbietowe. Zmiany utrzymywały się od 7 lat (ryc. 1). Skóra w okolicy stawów kolanowych, łokciowych i skokowych również była pogrubiona (ryc. 1). Zmianom nie towarzyszyła nadmierna potliwość. W wywiadzie nie odnotowano występowania podobnych objawów u członków rodziny. $W$ badaniu przedmiotowym stwierdzono postać rozlaną rogowca rąk i stóp z rumieniowym brzegiem, przechodzącego na powierzchnię grzbietową rąk i stóp. Obustronnie w okolicach stawów kolanowych i łokciowych oraz ścięgna Achillesa występowały hiperkeratotyczne blaszki. Nie wykazano zmian w obrębie włosów, paznokci i zębów. Nie stwierdzono nieprawidłowości w badaniu ogólnym ani w rutynowych badaniach dodatkowych. Badanie histopatologiczne wycinka skóry pobranego z powierzchni dłoniowej rąk wykazało nieregularną akantozę i nieznaczny naciek zapalny w obrębie skóry.

Choroba o szczególnym fenotypie klinicznym została opisana po raz pierwszy w 1952 roku przez Greithera i określona mianem keratosis extremitatum hereditaria progrediens [3]. Później w piśmiennictwie pojawiły się opisy przypadków tej samej jednostki chorobowej z określeniem transgradiens et progrediens [2-4]. Obraz schorzenia obejmuje głównie: nieepidermolityczny rogowiec rąk i stóp (palmoplantar keratoderma - PPK) odgraniczony od skóry zdrowej rumieniowym brzegiem, przechodzący także na powierzchnię grzbietową (transgrediens) oraz zajęcie po- 

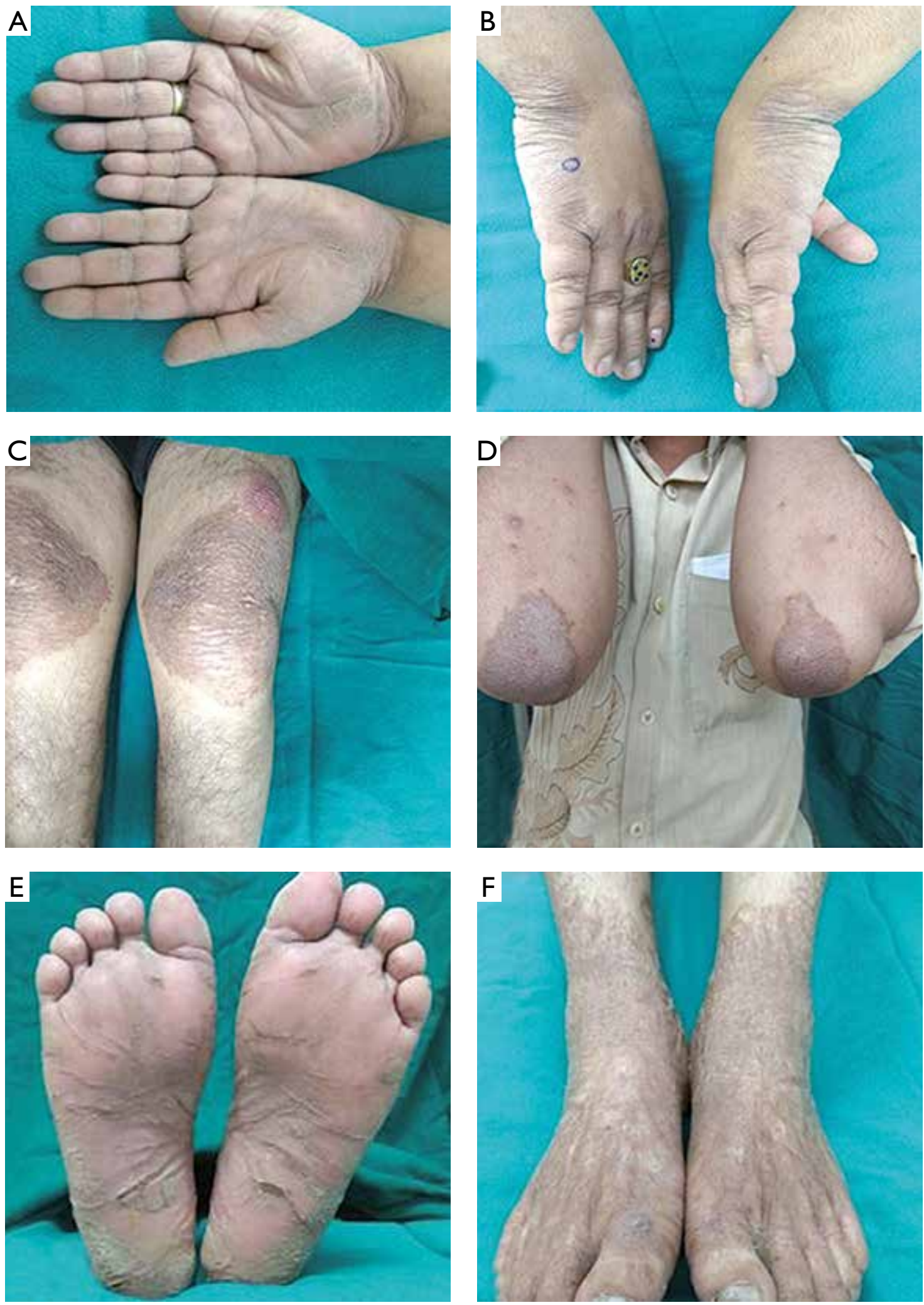

Figure I. A - Thickening of both palm extending to volar aspect of wrist. B - Thickening of skin extending to dorsal aspect of hands. C - Thickening of skin over both knee. D - Thickening of skin over both elbows. E - Thickening of both sole. F - Thickening of dorsum of feet extending to ankle joint

Rycina I. A - Obustronne zgrubienie skóry dłoni przechodzące na stronę dłoniową nadgarstka. B - Zgrubienie skóry przechodzące na stronę grzbietową rąk. C - Obustronne zgrubienie skóry w okolicy stawu kolanowego. D - Obustronne zgrubienie skóry w okolicy stawu łokciowego. E - Obustronne zgrubienie skóry podeszew stóp. F - Zgrubienie skóry na powierzchni grzbietowej stóp przechodzące na skórę stawu skokowego 
phenotype, there have been recent doubts on its existence as a discrete entity. It is believed by some to be an extensive variant of the Unna-Thost palmoplantar keratoderma [1]. However, the distinct features of the latter such as early age of onset before 2 years, lack of transgrediens and absence of spatial involution are not seen in Greither's disease. The treatment is difficult like all PPKs, and treatment options include salt water soaks with paring, topical keratolytics and systemic retinoids [7].

We report this case in view of the classical clinical findings which distinguish it from other non-epidermolytic PPKs and late onset of disease.

\section{CONFLICT OF INTEREST}

The authors declare no conflict of interest. wierzchni zgięciowych nadgarstków (progrediens) i okolicy ścięgna Achillesa [5]. Na skórze w okolicy stawów kolanowych i łokciowych mogą występować hiperkeratotyczne blaszki. Obserwuje się także nadmierne wydzielanie potu [6]. Obraz histopatologiczny nie jest swoisty i obejmuje akantozę oraz ortohiperkeratozę. Chociaż choroba Greithera cechuje się wyjątkowym fenotypem, ostatnio pojawiają się wątpliwości co do zasadności jej klasyfikacji jako odrębnej jednostki chorobowej. Zdaniem niektórych badaczy schorzenie należy uznać za rozsiany wariant rogowca rąk i podeszew Unny-Thosta [1]. Za rozróżnieniem tych dwóch jednostek przemawiają jednak charakterystyczne cechy rogowca Unny-Thosta, czyli rozwój choroby w wieku poniżej 2 lat, brak tendencji do transgrediencji oraz brak zmian inwolucyjnych. Cechy te nie dotyczą choroby Greithera. Leczenie jest trudne, podobnie jak w przypadku każdej postaci rogowca rąk i stóp. Dostępne opcje terapeutyczne obejmują: kąpiele miejsc objętych zmianami w wodzie z solą oraz usuwanie zrogowaciałej skóry, stosowanie miejscowych środków keratolitycznych i leczenie ogólne retinoidami [7].

Przypadek przedstawiono ze względu na klasyczny obraz kliniczny rogowca dłoniowo-podeszwowego $\mathrm{z}$ tendencją do transgrediencji i progrediencji, który różnicuje go od innych nieepidermolitycznych postaci rogowca rąk i stóp, oraz z uwagi na późny początek choroby.

\section{KONFLIKT INTERESÓW}

Autorzy nie zgłaszają konfliktu interesów.

\section{References}

Piśmiennictwo

1. Tay Y.K.: What syndrome is this? Greither syndrome (Transgrediens et progrediens palmoplantar keratoderma). Pediatr Dermatol 2003, 20, 272-275.

2. Flückiger R., Itin P.H.: Keratosis extremitatum (Greither's disease): clinical features, histology, ultrastructure. Dermatology 1993, 187, 309-311.

3. Arif T., Adil M., Amin S.S., Dorjay K.: Transgrediens et progrediens palmoplantar keratoderma: a case of Greither's disease. Przegl Dermatol 2017, 104, 66-67.

4. Dominguez Au on J.D., De Argila Fernandez-Duran D., Rivera Diaz R., Rodriguez Peralto J.L., Guerra Tapia A., Iglesias Diez L.: Progressive diffuse keratoderma (Greither's disease). Actas Dermosifil 1997, 88, 119-122.

5. Singh T., Yadav S., Dhillon K.S., Khan N., Khan A., Srivastava S., et al.: Greither's disease: a case report. Int J Adv Med 2015, 2, 251-253.

6. Athanikar S.B., Inamadar A.C., Palit A., Sampagavi V.V., Deshmukh N.S.: Greither's disease. Indian J Dermatol Venereol Leprol 2003, 69, 292-293.

7. Ratnavel R.C., Griffiths W.A.: The inherited palmoplantar keratodermas. Br J Dermatol 1997, 137, 485-490.

Received: 16.08 .2019

Accepted: 19.10 .2019

Otrzymano: $16.08 .2019 \mathrm{r}$.

Zaakceptowano: 19.10.2019 r.

How to cite this article

Sinha S., Bansal P., Dorjay K., Vats G.: A case of Greither's disease with late onset of disease: a rare presentation. Dermatol Rev/ Przegl Dermatol 2019, 106, 545-547. DOI: https://doi.org/10.5114/dr.2019.90003. 